\title{
El espíritu burlón de los masoretas
}

\author{
Emilia FERNÁNDEZ TEJERO * \\ Instituto de Filología - CSIC, Madrid
}

Cuando en 1941 el comediógrafo británico Noel Coward estrenó Blithe Spirit, probablemente desconocía la existencia de los masoretas. Pero me he permitido usurpar el título de su obra porque, al igual que en ella un espíritu burlón encarnado en una doncella simplona tiene en jaque a cuatro personajes racionalistas y escépticos, al interpretar algunas notas masoréticas puede percibirse un sutil transfondo de bromas inteligentes, de guiños festivos, con los que los masoretas parecen buscar la complicidad de los colegas que conocían perfectamente el Antiguo Testamento y se movían en la misma onda religiosa y textual.

El investigador moderno que, salvo escasas excepciones, no está tan familiarizado con el texto bíblico como lo estuvieron los masoretas, puede sentirse, en ocasiones, incomodado por la dificultad que implica el desciframiento de algunas de las noticias, sea por su concisión, sea por lo que tienen de juego, cuyas claves hay que descubrir. Pero si tiene interés y sentido del humor, acaba seducido y se siente invitado a incorporarse a la partida. Llega un momento en el que no quiere librarse de esos espíritus burlones, sino que, por el contrario, intenta dialogar con ellos, comprender qué, por qué y cómo nos transmitieron sus conocimientos. Se acepta el reto y, tras

*tejero@filol.csic.es.

Sefarad 63 (2003) págs. 33-42

(c) CSIC

ISSN 037-0894 
descifrar una masora especialmente difícil, se siente el deseo de susurrar: «esta vez he estado a tu altura; vamos por otra».

Pese a lo que pueda creerse respecto a la Masora -si es que se cree algo, porque, en general, es una ciencia escasamente utilizada en la crítica textual ${ }^{1}$ - sus anotaciones no son meramente numéricas. Los masoretas fueron auténticos críticos textuales: dotaron al texto consonántico de vocales y signos de cantilación, elaboraron notas relativas a la grafía correcta de las palabras, al número de veces en que una forma concreta, sola o en combinación con otras, aparece escrita de una manera determinada, especificaron la forma correcta en la que debían escribirse palabras que podían dar lugar a confusión; trataron de las preposiciones que acompañan a determinadas formas verbales (a modo de phrasal verbs), tuvieron auténticas percepciones gramaticales ${ }^{2} \mathrm{e}$ incluso incluyeron en sus notas matices exegéticos tales que ha de recurrirse a algún Midrás para comprender mejor determinadas informaciones ${ }^{3}$. Y siempre con la finalidad de asegurar la transmisión correcta del texto bíblico, como se sintetiza en la clásica frase de R. Aqiba: «La masora es el cerco protector de la ley». Bien es verdad que en ese cerco se abrieron algunas brechas, hasta el punto de que en el siglo XVII Y. S. de Norzi hubo de escribir una larga y densa obra masorética que denominó Goder Peres ${ }^{4}$, con la finalidad de repararlas.

\footnotetext{
${ }^{1}$ Para una aproximación inicial, muy completa, a esta ciencia, cf. A. Dotan, «Masorah», Encyclopaedia Judaica 16 (Jerusalén 1971) cols. 1401-1482, e I. YEIVIN, Introduction to the Tiberian Masorah, translated and edited by E. J. REVELL (Missoula, Montana 1980).

2 Cf. A. Dotan, "מן המסורה אל הדקדוק», Lěšonénu 54 (1990) págs. 155-168 y E. FERnÁndez TEJERo, «Masora or Grammar Revisited», en Proceedings of the Twelfth International Congress of the International Organization for Masoretic Studies, ed. E. J. REVELL (s. 1. 1995) págs. 11-23.

${ }^{3}$ En un estudio de reciente publicación, E. MARTín CONTRERAS, La interpretación de la creación. Técnicas exegéticas en Génesis Rabbah (Estella 2002) ha dedicado un capítulo completo a los antecedentes masoréticos en la literatura rabínica (págs. 147-205).

4 «Tapiador de brechas», tomado de Isaías 52,18. La primera edición de la obra se debe a Rafael Hayyim Barsila (Mantua 1742-1744), quien le dio el título de Minhat $\check{S} a y$.
} 
Es también usual el acusar a los estudios masoréticos de difíciles y áridos. Creo que todos cuantos nos dedicamos a estos estudios estamos de acuerdo con lo primero ${ }^{5}$, pero en desacuerdo con lo segundo. Porque la Masora es un jocoso (en su etimología más pura) prodigio de ingenio, imaginación y fantasía.

Una de las obras en las que puede percibirse con mayor claridad la mentalidad de los masoretas es el Sefer 'Oklah we- 'Oklah ${ }^{6}$, tratado formado por listas de contenido diverso y precedidas siempre por un encabezamiento descriptivo. El lector familiarizado con el texto bíblico no se extrañará de que entre esas listas aparezcan las que recogen los pasajes en los que hay escrita alguna letra de tamaño mayor o menor dispersas por el Antiguo Testamento; las relativas al kĕtîblquěrê; al nûn invertido, a palabras escritas que no han de leerse, o no escritas, que sí; a correcciones clásicas de los escribas. Es decir, a fenómenos que tienen su expresión gráfica en el texto y que se perciben con el uso frecuente del mismo. Pero veamos otro tipo de encabezamientos ${ }^{7}$, a primera vista sorprendentes:

- Lista 1: lista alfabética de casos únicos ${ }^{8}$, uno no precedido de l y otro sí.

${ }^{5}$ Un solo ejemplo tomado del manual de P. H. Kelley, D. S. MynatT y T. G. CRAWFORD, The Masorah of Biblia Hebraica Stuttgartensia. Introduction and Annotated Glossary (Michigan, U. K. 1998) pág. XI: «... one should have no illusions about the complexities of this vast field of study. It would require a lifetime to master it».

${ }^{6}$ Editado por S. FrensdorfF, Das Buch Ochlah W'ochlah (Massora) (Hannover 1868), para cuya utilización resulta de gran ayuda la obra de B. OGNIBENI, Index biblique à la "Ochlah w'ochlah» de S. Frensdorff (Torino 1987); F. DíAz ESTEBAN, Sefer 'Oklah we-'Oklah (Madrid 1975) y B. OGNIBENI, La seconda parte del Sefer 'oklah we'oklah (Madrid 1995).

${ }^{7}$ A partir de la edición de S. FRENSDORFF; en la traducción se pierde, lamentablemente, el carácter conciso y plagado de abreviaturas del hebreo original. Para la traducción de los versículos bíblicos sigo la edición de F. CANTERA BURGOS y M. IGLESIAS GONZÁLEZ, Sagrada Biblia ( $3^{\mathrm{a}}$ ed. Madrid 2000), salvo cuando la interpretación de los juegos de palabras requiere una traducción aún más literal que la del propio F. Cantera.

${ }^{8}$ Palabras lêt, palabras que aparecen una sola vez. 


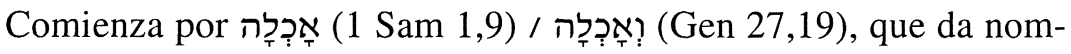
bre al tratado, y finaliza con ותרוֹרוֹ / (Is 25,5 (Neh 9,13).

- Lista 37: lista alfabética de palabras que aparecen una sola vez, cuyas dos primeras letras se siguen en orden alfabético.

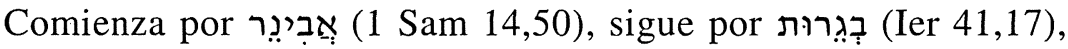

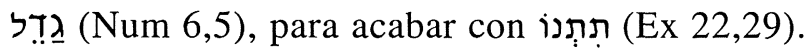

- Lista 79: lista alfabética de palabras que aparecen precedidas את (nota de acusativo), pero nunca de ואת (la misma nota, precedida de la conjunción copulativa).

Sorprende que entre ellas se encuentren palabras de tan frecuente

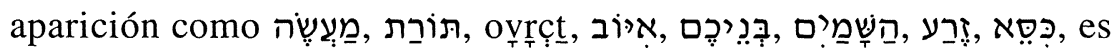
decir, 'Abraham', 'Iob', 'vuestros hijos', 'los cielos', 'simiente', 'silla o trono', 'obra', 'ley de'.

- Lista 90: dieciocho parejas de palabras que aparecen una a principio y otra a final de versículo.

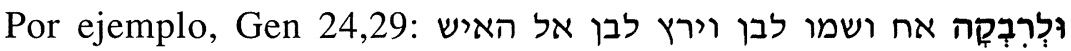
החוצה אל העין (Tenía Rebeca [literalmente, y para Rebeca] un hermano llamado Labán, el cual corrió afuera hacia el hombre, a la fuente...); Gen 26,35: ותהיין מרת רוח ליצחק וּלְרבְָקה (fueron motivo de amargura de espíritu para Isaac y para Rebeca).

- Lista 164: siete versículos de quince palabras en los que la palabra central es un kétît $\underline{b} / q \breve{e r} \hat{e}$.

Por ejemplo, 1 Sam 13,19: וחרש לא ימצה בכל ארץ ישראל כי אמר פרוך פלשתים פן יעשו העברים חרב או חנית (Ahora bien, no se encontraba un herrero en todo el país de Israel, pues los filisteos habíanse dicho: «iPara que no fabriquen los hebreos ni espadas ni lanzas!») ${ }^{9}$.

\footnotetext{
${ }^{9}$ Evidentemente, el cómputo masorético se pierde en la traducción al español.
} 
- Lista 232: dos grupos de tres versículos en los que la misma palabra va precedida de en los dos primeros casos y no va precedida de את en tercero.

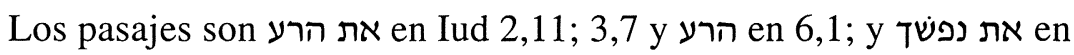
Ez 3,19; 3,21 y נפשר en 33,9.

- Lista 274: veinte versículos que pueden dar lugar a error; catorce de ellos tienen un orden propio; con indicación de los que llevan 1 y de los que no lo llevan.

Se refiere a veinte versículos en los que se mencionan los pueblos de Palestina con diferencias en el orden de enunciación y en los nombres que van o no precedidos de la conjunción copulativa. Por ejemplo, Ex 23,23: האמרי והחתי והפרזי והכנעני החוי והיבוסי (el amorreo, y el hittita, y el perezeo, y el cananeo, el hiwweo y el yebuseo); Ex 33,2: הכנעני האמרי והחתי והפרזי החוי והיבוסי (el cananeo, el amorreo, y el hittita, y el perezeo, el hiwweo y el yebuseo).

- Lista 296: ocho versículos en los que una palabra aparece cuatro veces y la tercera vez es algo diferente de las restantes.

Por ejemplo, Gen 41,26: שבע פרת הטבת שבע שנים הנה ושבע השבלים (Las siete novillas hermosos representan siete años, y las siete espigas lucidas simbolizan siete años...).

- Lista 316: tres versículos de ochenta letras que empiezan por וכל.

Los pasajes son Gen 2,5; Num 36,8; Ios 11,14.

- Lista 357: once versículos en los que וגם es la antepenúltima palabra.

Por ejemplo, Ex 21,29; Ios 7,11; Ez 16,28.

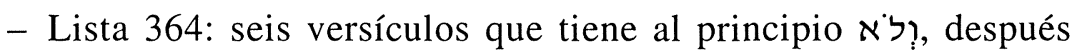
לִ y después וְל 


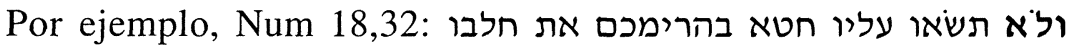
(y no incurriréis con este motivo en pecado alguno; así no profanaréis las cosas santas de los hijos de Israel, y no moriréis).

¿En qué mentes surgieron estos sueños de la razón que no engendraron monstruos, sino estructuras precisas, instrumentos de trabajo indispensables, que contribuyeron a proteger durante siglos el texto sagrado? No conozco un fenómeno similar en la historia de la crítica textual; ni siquiera puede compararse con el trabajo que la escuela de filólogos de Alejandría dedicó al texto de Homero. Bien es verdad que el carácter religioso de los libros sobre los que se trabajó y la necesidad de las comunidades judías de tener un texto minuciosamente fijado, casi monolítico, que les permitiera mantener la unidad religiosa en la diáspora, justifican la tarea ingente que llevaron a cabo primero los sôfěrîm y después los masoretas.

La pedagogía prima en todas las informaciones: en las de Masora Parva, generalmente de carácter numérico; en los desarrollos correspondientes de la Masora Magna, por medio de sîmanîm ${ }^{10}$; en listas como las que acabamos de ver. La masora es una larga cadena de caveat que obligaba al escriba a prestar una atención minuciosa al texto, que le prevenía de posibles errores, que revelaba un interés infinito por la perfección y acribía con las que ese texto había de transmitirse.

Otro fenómeno que revela el carácter didáctico de la masora es la utilización de fragmentos de versículos, versículos enteros o frases inventadas, de carácter mnemotécnico -casi siempre en arameoque ayudaban a recordar los pasajes afectados por una misma regla. Para lograr el efecto deseado se necesitaba una selección cuidadosa de las palabras de los versículos a los que aludía esa regla.

\footnotetext{
${ }^{10}$ Palabra, palabras e incluso largos fragmentos de versículos que sirven de clave para identificar los pasajes afectados por la noticia.
} 
Algunos ejemplos ${ }^{11}$ :

- En una masora magna de Gen 41,25 del códice M1 se lee:

el primero, lo que Dios ha manifestado; el segundo, lo que ha mostrado; y hay un versículo que lo indica: y Samuel temía manifestar la visión.

Se trata de dos versículos muy próximos, de texto parecido: Gen 41,25: אשר האלהים עשה הגיד לפרעה (Lo que Elohim va a realizar lo ha אשר האלהים עשה הראה את פרעה :manifestado al faraón); Gen 41,28 (Lo que Elohim va a realizar lo ha hecho ver al faraón). En el primero, sin embargo, se utiliza el verbo נג = 'manifestar', y en el segundo el verbo ראה, 'ver'; en 1 Sam 3,15 aparecen las dos raíces

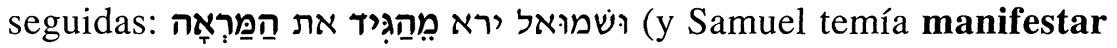
la visión).

- En una masora magna de 2 Reg 18,20 del códice B19a se lee:

el de Reyes, has dicho que una palabra de los labios; el de Isaías, he dicho que una palabra de los labios; $y$ hay un versículo que lo indica: $\mathrm{Y}$ llamó 'Abimelek a Isaac y le dijo: evidentemente es tu esposa, ¿cómo has dicho? Porque he dicho.

Se trata de evitar la confusión entre dos pasajes similares, en los

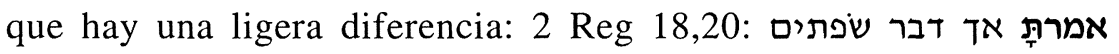
אמר לHas dicho que una mera palabra de los labios es

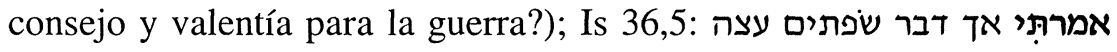

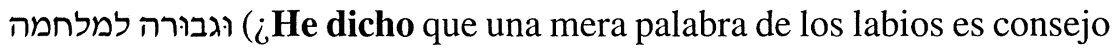
y valentía para la guerra?). En este caso se trata de la persona del verbo

\footnotetext{
${ }^{11}$ Están tomados del códice B19a de Leningrado, en la edición facsimilar de D. N. Freedman, The Leningrad Codex (Grand Rapids 1998), y del códice M1 de la Biblioteca de la Universidad Complutense de Madrid. He utilizado la masora impresa por G. E. WEIL, Massorah Gedola (Roma 1971) para la Biblia Hebraica Stuttgartensia como un instrumento de trabajo más. El texto de Weil en los Prolegomena de esta Biblia describe bien en qué consiste el elaboravit que se le atribuye en la portada.
} 


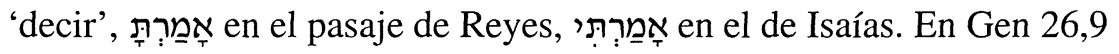

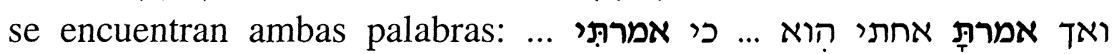
(«¿cómo, pues, has dicho: 'Es mi hermana'? ... Porque me dije ...»). En las traducciones al español más utilizadas en la actualidad ${ }^{12}$, en ambos pasajes se emplea la segunda persona, obviando la información masorética.

- En Iud 2,11, a propósito de la palabra אַעלה, dice la masora del códice B19a:

aparece ocho veces, y los pasajes son: dijo el ángel a la mujer de Arauná largo cubrir incienso Jerusalén.

El lector de esta masora se encuentra con una frase mnemotécnica inventada que le ayudará a recodar los versículos a los que afecta la información: «Dijo (Ex 3,17) el ángel (Iud 2,1) a la mujer (1 Sam 28,11) de Arauná (2 Sam 24,24): ¿sería largo [costaría mucho] (Ier 30,17) cubrir (Ier 46,8) de incienso (Ps 66,15) Jerusalén? (Ps $137,6) »$.

- En Ier 8,4, a propósito del conjunto ולא ישוב, dice la masora del códice B19a:

aparece seis veces y los pasajes son: ley juró y cayó el león se acordó y se rió.

La frase de carácter mnemotécnico sería: «Por la ley (Deut 28,31) juró (Is 45,23), y se cayó (Ier 8,4) el león (Prov 30,30); se acordó (Ps 78,39) y se rió (Iob 39,22)».

Hasta en masoras aparentemente sencillas puede descubrirse un juego. Es relativamente frecuente que en la masora magna se den primero los simanîm en arameo («en la lengua del Targum»), de

12 La ya citada de F. CANTERA Burgos y M. Iglesias GonZÁlez, Sagrada Biblia y la de L. Alonso SchöKel y J. Mateos, Nueva Biblia española (Madrid 1975). 
forma muy breve, y después en hebreo, de manera más extensa. Pues bien, en la masora magna del códice M1, a propósito de העלמה, se dice en Gen 24,43:

aparece tres veces y sus sîmanîm, en la lengua de Targum, son: la joven del faraón concebirá; y su explicación es...

Continúa con los sîmanîm en hebreo. Además del carácter mnemotécnico de la frase resultante, la broma radica en que la palabra 'joven' aparece en los tres pasajes implicados: Gen 24,43; Ex 2,8 e Is 4,14 . Sólo por exclusión se acaba atribuyendo ese sîman al caso de Génesis.

Si en otra ocasión intenté demostrar el interés que la masora puede tener en concreto para los exegetas ${ }^{13}$, ahora pretendo animar a los científicos de campos afines a que se adentren en esta ciencia, ocasionalmente críptica, pero utilísima a la hora de interpretar el texto.

Ciencia que, además, puede proporcionar ratos amenos, plantear retos ingeniosos, ayudar a disciplinarse con sus ritos, y a intentar tapiar los ocasionales rotos que se hayan producido en el entramado de sus noticias a lo largo de los siglos. Porque, utilizando sus apasionantes rutas, se logrará dar a la masora el lugar privilegiado que merece a la hora de comprender e interpretar el texto bíblico ${ }^{14}$.

${ }^{13}$ E. FerÁNDEZ TEJERo, «Masora y Exégesis», en Simposio Bíblico Español, eds. N. Fernández Marcos, J. Trebolle Barrera y J. Fernández Vallina (Madrid 1984) págs. 183-191.

${ }^{14}$ El lector que tenga sensibilidad masorética habrá descubierto de inmediato el sencillo juego de palabras contenido en el último párrafo; esta nota va dirigida a quien no tenga esa sensibilidad. 


\section{RESUMEN}

En este artículo la autora trata de interesar en los estudios masoréticos a los especialistas en la crítica textual del texto bíblico que trabajan en campos afines. Intenta minimizar el carácter habitualmente atribuido a los estudios masoréticos de difíciles y aburridos, demostrando que los masoretas, además de magníficos estudiosos del texto hebreo, usaron métodos repletos de humor para transmitir informaciones textuales de todo tipo.

PALABRAS ClAVE: Biblia, crítica textual, Masora, humor.

\section{SUMMARY}

In this article the author tries to arouse the interest in Masoretic studies of scholars devoted to biblical textual criticism or related fields of research. She intends to minimize the difficult and boring character usually attributed to the studies on Masorah, showing that the Masoretes, besides being magnificent Hebrew Biblical scholars, used humorous devices to hand down some of their textual informations.

KEYWORDS: Bible, textual criticism, Masorah, humor. 